\title{
How can I support a colleague who is being investigated?
}

\author{
It can be hard to know what you can do for a colleague who is under investigation. Abi Rimmer \\ speaks to three experts about the best ways to offer support
}

Abi Rimmer

The BMJ

\section{Advocate for their wellbeing}

Christian Harkensee, consultant paediatrician, coach, and mentor, says, "Being formally investigated will cause shock and stress. There may be feelings of shame and guilt but also, given the high levels of identification doctors have with their work, enormous feelings of threat for their job, career, and life.

"Sadly, too often NHS employers don't handle these cases very well, and doctors end up with long term depression, embitterment, or even suicide.

"As a colleague, one of the best things you can do is to ask, 'How are you doing? Are you OK? Is there any way I can help?' Break through the isolation, be there, listen, and show compassion.

"Research has shown that talking to a colleague who is also a friend can really help, because often they understand the situation best. Try to discourage maladaptive thoughts by giving other perspectives on what has happened. Encourage them to keep to routines and maintain interests outside medicine that could provide them with an experience of success and achievement.

"Notice the signs of deteriorating mental health-poor sleep, expressions of hopelessness, loss of routines, or changes in eating or drinking habits-and advise them to seek professional support. It may save their life.

"Most of all, be an advocate for your colleague's wellbeing within your organisation. Without getting directly involved, speak to human resources, the medical director, or chief executive about how important colleague contact is for the doctor, and discuss whether they could be allowed to work in some other capacity, such as in research, teaching, or audit.

"Encourage management to conduct the investigation proportionately, in a timely manner, and with fairness, transparency, honesty, and compassion. External, independent input may be key.

"Recent guidance from NHS Improvement $t^{1}$ requires organisations to act fairly and objectively. A poorly conducted investigation or disciplinary process can damage relationships and a doctor's confidence and capabilities, and may prove costly for all concerned. This is neither in the doctor's nor the employer's interest."

\section{Remind them that others go through this}

Narinder Kapur, visiting professor of neuropsychology at UCL, says, "I would say to a colleague who is under investigation that the key things to do are to stay calm, take expert advice, and don't say or do anything on impulse that you may later regret.

"Advise them that they can seek advice from the BMA and the protection body they belong to, but in general they will first need to find out as much as possible about the nature of the investigation.

"Tell them that they need to try to be objective in ascertaining the facts about the concerns that have been raised, and try to see things from the perspective of the employer. Remind them that the most important thing is the physical and mental wellbeing of themselves and their family.

"Encourage them to get involved in enjoyable activities with family and close friends and avoid the temptation of alcohol or drug abuse. Wellbeing matters are often more critical than financial considerations, and they may find it helpful to explore relevant websites and guides. ${ }^{23}$

"It's helpful to try and see things from a patient safety perspective, so make sure that their statements and actions reflect this. If their employer seems to be intractable, let them know that in some cases it may be worth considering an approach to their local MP.

"Where the whole process appears to be getting nowhere, and it's possible for them to get a job with another employer, then encourage them to take that step.

"Seeking advice from as many trusted colleagues as possible, especially those who have been through a similar ordeal, can also help. Remind them that many doctors do go through this, including referral to the GMC, and come out unscathed and have a fulfilling career. Even the former chair of the GMC, Terence Stephenson, was investigated twice and exonerated.

"Encourage them to try and see the whole matter in this broader perspective; it may look less of a major problem five years down the line.

"If a doctor has made mistakes, they should be truthful and humble, and admit to them. Those who succeed in life are those 
who admit to their failures, learn lessons, and come out stronger by making active attempts to change their habits and behaviour."

\section{Encourage self care}

Richard Duggins, consultant psychiatrist in medical psychotherapy with Cumbria, Northumberland, Tyne, and Wear Foundation Trust and NHS Practitioner Health, says, "Doctors typically cope with adversity by knuckling down and getting on with it. Support your colleague to recognise that an investigation requires a different approach. They need to be proactive, rather than just keeping their head down. An investigation is a major stressor, and evokes anxiety in even the most self assured. Many doctors are already working beyond their capacity and, unless we look after ourselves, an investigation can be the straw that breaks the camel's back. A significant proportion of doctors can start to feel psychologically unwell, hopeless, or even have suicidal thoughts.

"I recommend you use care, compassion, and, if necessary, persistence to support your colleague. Now is the time for them to "try easier" rather than try harder, so encourage them to create time to recharge by reducing some demands at work and home. "Investigations make most doctors feel unhappy, awkward, and ashamed, and your colleague will be tempted to withdraw from pleasurable activities and social support. They may even try to withdraw from you. They need encouragement to engage in more replenishing activities. If they are away from work, help them overcome the demoralising isolation by establishing a daily routine.

"Ensure they seek support from their organisation, their defence union, and the BMA, and encourage them to follow their advice. Help them to find and talk with a colleague who has gone through something similar and point them in the direction of the BMA's wellbeing support directory. ${ }^{4}$ If they start to feel psychologically unwell, then strongly encourage them to act quickly to nip things in the bud through seeing their GP, occupational health, or self referral to services like NHS Practitioner Health.”

1 NHS Improvement. Provider bulletin: 5 June 2019: learning lessons to improve our people practices. https://improvement.nhs.uk/news-alerts/provider-bulletin-5-june-2019/\#improvingour-people-practices.

2 Clinical Excellence. www.clinicalexcellenceuk.com.

3 Doctors' Support Network. www.dsn.org.uk/join-dsn.

4 BMA. Sources of support. 27 September 2019. www.bma.org.uk/advice/work-life-support/ your-wellbeing/sources-of-support.

Published by the BMJ Publishing Group Limited. For permission to use (where not already granted under a licence) please go to http://group.bmj.com/group/rights-licensing/ permissions 